\title{
Vacancy-engineering implants for high boron activation in silicon on insulator
}

\author{
A. J. Smith, ${ }^{\text {a) }}$ N. E. B. Cowern, R. Gwilliam, and B. J. Sealy \\ Advanced Technology Institute, University of Surrey, Guildford, GU2 7XH, United Kingdom \\ B. Colombeau \\ Chartered Semiconductor Manufacturing Ltd, 60 Woodlands, Industrial Park D, Street 2, Singapore 738406 \\ E. J. H. Collart \\ Applied Materials UK Ltd, Foundry Lane, Horsham, RH13 5PX, United Kingdom
}

S. Gennaro, D. Giubertoni, M. Bersani, and M. Barozzi

ITC-irst, via Sommarive 18, 38050 Povo (Trento), Italy

(Received 7 November 2005; accepted 12 January 2006; published online 24 February 2006)

\begin{abstract}
The formation of boron interstitial clusters is a key limiting factor for the fabrication of highly conductive ultrashallow doped regions in future silicon-based device technology. Optimized vacancy engineering strongly reduces boron clustering, enabling low-temperature electrical activation to levels rivalling what can be achieved with conventional preamorphization and solid-phase epitaxial regrowth. An optimized $160 \mathrm{keV}$ silicon implant in a 55/145 nm silicon-on-insulator structure enables stable activation of a $500 \mathrm{eV}$ boron implant to a concentration $\sim 5 \times 10^{20} \mathrm{~cm}^{-3}$. (ㅇ 2006 American Institute of Physics. [DOI: 10.1063/1.2178487]
\end{abstract}

As $p$-type metal-oxide-semiconductor devices evolve into the $45 \mathrm{~nm}$ technology window and beyond, requirements for ultrashallow junctions in terms of junction depth and sheet resistance are becoming increasingly stringent. Low resistance is foreseen as the most difficult goal to achieve, as excess silicon interstitials remaining after implantation hinder boron activation by driving the formation of boron-interstitial clusters (BICs), ${ }^{1-3}$ which are highly stable and mostly electrically inactive. A key challenge in achieving the desired specifications is thus to find ways to prevent BIC formation. ${ }^{4,5}$ Techniques such as preamorphization and solid-phase epitaxial regrowth (SPER) can enhance boron electrical activation above solid solubility, ${ }^{6}$ but end of range damage, left in the crystalline phase after SPER is completed, provides excess interstitials that drive BIC formation during subsequent annealing. ${ }^{7}$ Furthermore, as silicon-on-insulator (SOI) substrates increase in importance, the integration of techniques based on preamorphization may be problematic, especially for fully depleted devices. ${ }^{8}$

This letter reports on an optimized vacancy engineering technique as a potential rival to preamorphization and SPER. The method relies on the inherent properties of ion implantation, which produces Frenkel pairs in which the vacancy and interstitials are spatially separated due to the momentum transfer from the incident ion. This leaves a net excess of vacancies close to the surface and a corresponding excess of interstitial atoms around the ion projected range. ${ }^{9}$ The excess vacancies close to the surface improve the properties of a subsequent boron implant by annihilating the excess interstitials needed for BIC formation, thus facilitating an increase in electrical activation of boron.

The presence of a deeper band of interstitial defects might be seen as a disadvantage of vacancy engineering, because, as in the case of SPER (Refs. 7 and 5) interstitials

a) Author to whom correspondence should be addressed; electronic mail:
a.j.smith@surrey.ac.uk diffusing back from this band could cause deactivation at longer annealing time scales. In early vacancy engineering studies, this was not a problem as high-energy high-dose silicon co-implants were used, generating deep stable interstitial damage in the form of dislocation loops. ${ }^{10}$ However, much lower energies and doses are needed for compatibility with industrial silicon processes, and the shallower, less stable interstitial defects produced by such implants may cause deactivation. Previous work has shown that this difficulty with lower-energy coimplants can be overcome by the use of SOI substrates. ${ }^{11,12}$

When a vacancy engineering implant is performed in SOI and the silicon coimplant energy is designed such that the majority of the excess interstitials are recoiled beyond the depth of the silicon top layer, it is difficult for them to diffuse back through the buried oxide (BOX) and annihilate with the generated vacancies at the surface. ${ }^{11}$ This enables a much lower silicon coimplant energy to be used, with parameters dictated by the SOI structure. ${ }^{12}$ In this letter, we apply this approach to the activation of an ultrashallow boron implant with parameters typical for the next complementary-metaloxide-semiconductor technology generation. The results show stable activation levels well above previous reported values.

The experiments were performed on SOITEC SOI wafers having a 55/145 $\mathrm{nm}$ structure. The $160 \mathrm{keV}$ silicon coimplant was performed at a $7^{\circ}$ tilt and $22^{\circ}$ rotation to doses in the range from $4 \times 10^{14}$ to $1.1 \times 10^{15} \mathrm{~cm}^{-2}$ prior to a $500 \mathrm{eV}, 1 \times 10^{15} \mathrm{~cm}^{-2}$ boron implant. The projected range of the silicon implant places the peak of the excess interstitial region just below the $\mathrm{BOX}$, with a portion residing in the lower part of the buried insulator. Transmission electron microscopy images obtained after silicon implantation (not shown) indicate that the excess interstitial damage is isolated behind the BOX, leaving the top silicon free of the interstitial-type defects that occur when conventional preamorphization and SPER are used. Figure 1 shows the 


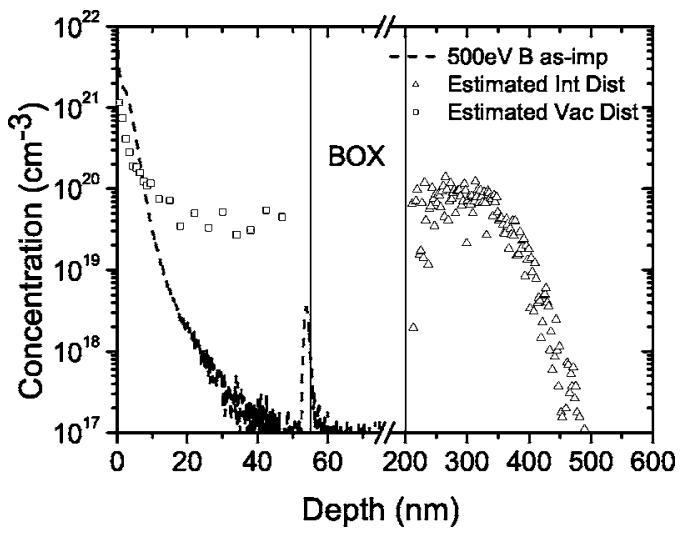

FIG. 1. Schematic of our experimental conditions, showing the SOI structure, the distributions of excess vacancies $(\square)$ and interstitials $(\triangle)$ resulting from our highest-dose $160 \mathrm{keV}$ silicon coimplant (estimated from Monte Carlo simulations), and the $500 \mathrm{eV}$ B implant profile (measured by SIMS).

distributions of ion-implanted boron [from secondary-ion mass spectrometry (SIMS)] and of ion-implanted vacancies and interstitials for the highest-dose coimplant (from Monte Carlo simulations) in relation to the dimensions of the SOI structure used in the experiment. To study the effects of the vacancies on the ultrashallow $p$-type layer, a $10 \mathrm{~s}$ isochronal annealing cycle $\left(500-1000^{\circ} \mathrm{C}\right)$ was used. Subsequently, samples were examined using SIMS and Hall-effect measurements to study the effects on diffusion and electrical activation, respectively. For this study a Hall scattering factor of unity has been assumed in order to estimate the hole concentration.

The measured sheet resistance, $R_{S}$, of the $p$-type layers is shown in Fig. 2 as a function of annealing temperature and coimplant dose. Without a silicon coimplant, $R_{s}$ follows a trend which has previously been observed and explained in terms of two key influences. ${ }^{12}$ First, a nonequilibrium process driven by interstitials causes boron to cluster into BICs at low temperature, the BICs starting to dissolve as the temperature is raised above $700{ }^{\circ} \mathrm{C}$. Secondly, equilibrium solid solubility of boron increases as a function of temperature in this range. The first effect is the major limitation on boron activation at low temperature; the second is more important at high thermal budgets as the solution of boron approaches equilibrium.

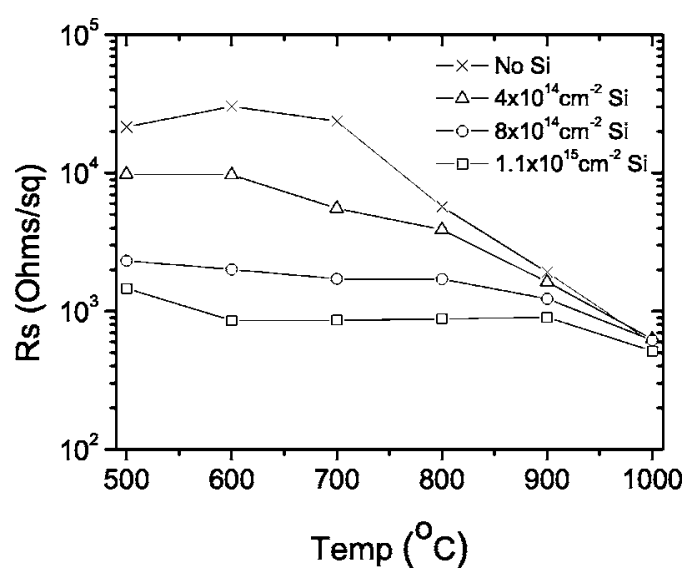

FIG. 2. $R_{s}$ measurements as a function of a $10 \mathrm{~s}$ isochronal annealing scheme of a $500 \mathrm{eV} \mathrm{B}$ implant, with and without $(\times)$ a $160 \mathrm{keV}$ silicon coimplant to doses of $4 \times 10^{14} \mathrm{~cm}^{-2}(\triangle), 8 \times 10^{14} \mathrm{~cm}^{-2}(\circ)$, and 1.1 $\times 10^{15} \mathrm{~cm}^{-2}(\square)$.

Downloaded 31 Mar 2009 to 131.227.178.132. Redistribution subject to AIP license or copyright; see http://apl.aip.org/apl/copyright.jsp

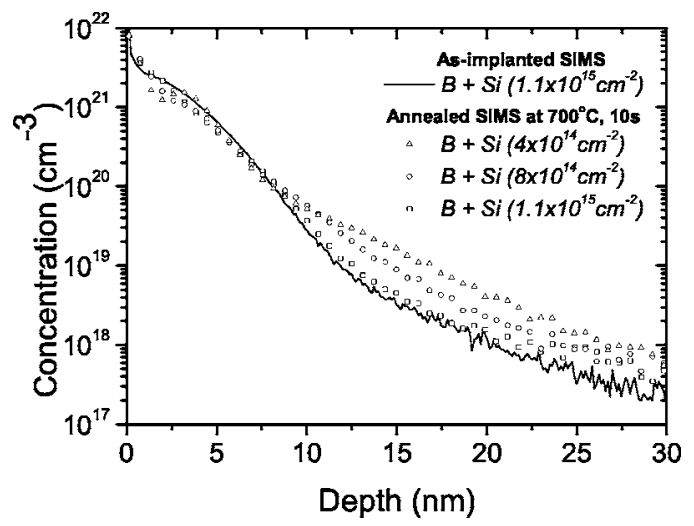

FIG. 3. SIMS analysis of $500 \mathrm{eV}$ B implants after silicon coimplantation, before and after annealing. Symbols show data for three coimplant doses: $4 \times 10^{14} \mathrm{~cm}^{-2}(\triangle), 8 \times 10^{14} \mathrm{~cm}^{-2}(\circ)$, and $1.1 \times 10^{15} \mathrm{~cm}^{-2}(\square)$, after annealing at $700{ }^{\circ} \mathrm{C}$ for $10 \mathrm{~s}$. The solid line shows the as-implanted profile (taken from the sample implanted with $1.1 \times 10^{15} \mathrm{~cm}^{-2}$ silicon).

By comparing the boron with and without a coimplant, one can see that all coimplants reduce the $R_{s}$ and the level of reduction increases monotonically with silicon dose (Fig. 2). Furthermore, the trends across all silicon doses are similar showing that at $1000{ }^{\circ} \mathrm{C}$ there is a negligible difference between the boron implant with or without the silicon coimplant. However, as the anneal temperature is reduced the effects of the coimplants become apparent, showing large reductions in $R_{s}$ which increase with decreasing annealing temperature down to $600{ }^{\circ} \mathrm{C}$. This shows that even with a coimplant the mechanisms discussed above still have a major effect on the boron layer. However, due to the presence of the excess vacancies it is possible to reduce the formation of BICs so that a greater fraction of the boron implant can become electrically active at low temperatures.

The highest dose silicon coimplant $\left(1.1 \times 10^{15} \mathrm{~cm}^{-2}\right)$ shows the greatest effect on the $R_{s}$. Comparing values with and without the $1.1 \times 10^{15} \mathrm{~cm}^{-2}$ silicon coimplant, it can be seen that the $R_{s}$ is reduced by a factor $\sim 30$ in the temperature range of $600-700{ }^{\circ} \mathrm{C}$. Hall-effect measurements show that at $700{ }^{\circ} \mathrm{C}$ this reduction arises from a factor $\sim 100$ improvement in sheet hole density $N_{s}$ (from $3.18 \times 10^{12}$ to $2.93 \times 10^{14} \mathrm{~cm}^{-2}$ ) and a resulting factor $\sim 3$ decrease in mobility (from 83 to $25 \mathrm{~cm}^{2} / \mathrm{V} \mathrm{s}$ ), due to ionized impurity scattering. Low-temperature activation of boron by vacancy engineering has previously been observed by Kalyanaraman et $a l .,{ }^{8}$ however, in that work the improvement in $N_{s}$ was only a factor of 2.5 .

Figure 3 shows the effects of silicon dose on diffusion at $700{ }^{\circ} \mathrm{C}$, corresponding to the $R_{s}$ values in Fig. 2. The effect of a boron implant without a silicon coimplant has been omitted from Fig. 3 as no measurable diffusion of the boron occurred. By correlating this with the low level of activation observed, it is concluded that at $700{ }^{\circ} \mathrm{C}$ the majority of the boron profile has evolved into BICs, resulting in an identical curve to the as-implanted case.

The diffused profile after the lowest silicon dose coimplant $\left(4 \times 10^{14} \mathrm{~cm}^{-2}\right)$, compared to the as-implanted profile, shows a significant amount of diffusion, resulting in a metallurgical junction depth of $X_{j} \sim 22 \mathrm{~nm}$ as defined at the $3 \times 10^{18} \mathrm{~cm}^{-3}$ level. A "kink" in the profile, known to form at the point at which the inactive/immobile part of the profile meets the active/diffusing portion, ${ }^{1}$ can be seen at a concentration level of $\sim 8 \times 10^{19} \mathrm{~cm}^{-3}$. At the next silicon dose 


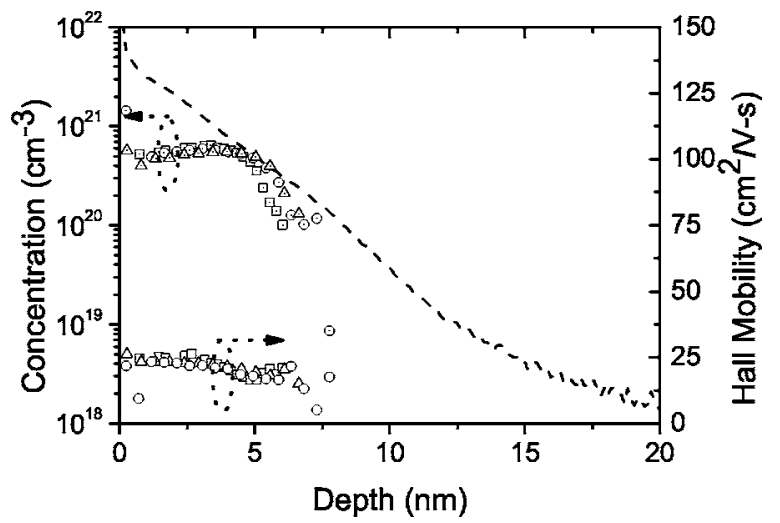

FIG. 4. Three differential Hall profiles showing the electrically active B profile for the $1.1 \times 10^{15} \mathrm{~cm}^{-2}$ silicon coimplant case after annealing at $700{ }^{\circ} \mathrm{C}$ for $10 \mathrm{~s}$. Also shown is the corresponding atomic profile measured by SIMS. The data demonstrate a very high activation level for this lowtemperature process.

$\left(8 \times 10^{14} \mathrm{~cm}^{-2}\right)$, there is less diffusion and $X_{j}$ has decreased to $\sim 19 \mathrm{~nm}$, while at the same time the kink occurs at a higher concentration of $\sim 1.4 \times 10^{20} \mathrm{~cm}^{-3}$, indicating a reduction in BIC formation. This trend continues with the highest silicon dose $\left(1.1 \times 10^{15} \mathrm{~cm}^{-2}\right)$ which shows a minimal amount of diffusion compared to the as-implanted profile.

At this highest dose, the small amount of diffusion makes it difficult to locate a kink in the boron atomic profile. Therefore, to estimate the level of activation, a differential Hall profiling technique was used. ${ }^{13}$ Three Hall profiles are shown in Fig. 4, indicating the reproducibility of the technique and consistently showing a peak carrier concentration of $\sim 6 \times 10^{20} \mathrm{~cm}^{-3}$. By integrating areas beneath these curves we obtain an average value of $N_{s}=2.7 \times 10^{14} \mathrm{~cm}^{-2}$, which is in good agreement with our earlier values from sheet measurements. Recently, Shao et $a l .{ }^{14}$ have reported boron activation levels above solid solubility using a combination of preamorphization and vacancy engineering implants with conventional SPER. In contrast, this work proves that-in SOI wafers at least-optimized vacancy engineering implants alone can achieve much greater levels of activation, at much lower annealing temperatures.

Before concluding this letter, we comment on the broader potential for the use of vacancy engineering. Suc- cessful application of vacancy engineering relies on preventing the majority of interstitials in the deep part of the coimplant distribution from reaching the boron and deactivating it. This can be achieved by a complete physical barrier as in the present work, by introducing traps for interstitials, by increasing the stability of the interstitial defects so that they dissolve less, or by lowering the processing temperature. We believe that particular solutions will be found for a variety of device architectures, making vacancy engineering a flexible and effective method for boron activation in future device technologies.

In summary, optimized vacancy generating implants are shown to be an efficient approach to inhibiting BIC formation. They work by reducing the supersaturation of interstitials present after the two-step sequence of a vacancy implant and a subsequent low-energy boron implant. This leads to a highly stable highly active $p$-type layer without the need for conventional preamorphization and SPER, or the use of advanced annealing schemes.

${ }^{1}$ N. Cowern, K. Janssen, and H. Jos, J. Appl. Phys. 68, 6191 (1990).

${ }^{2}$ P. Stolk, H.-J. Gossmann, D. Eaglesham, D. Jacobson, C. Rafferty, G. Gilmer, M. Jaraiz, J. Poate, H. Luftman, and T. Haynes, J. Appl. Phys. 81, 6031 (1997).

${ }^{3}$ M. Cogoni, A. Mattoni, B. Uberuaga, A. Voter, and L. Colombo, Appl. Phys. Lett. 87, 191912 (2005).

${ }^{4}$ ITRS 〈http://public.itrs.net〉 (2004).

${ }^{5}$ B. Pawlak, R. Surdeanu, B. Colombeau, A. Smith, N. Cowern, R. Lindsey, W. Vandervorst, B. Brijs, O. Richard, and F. Cristiano, Appl. Phys. Lett. 84, 2055 (2004).

${ }^{6}$ R. Lindsey, B. Pawlak, P. Stolk, and K. Maex, Mater. Res. Soc. Symp. Proc. 717, C2.1 (2002).

${ }^{7}$ B. Colombeau, A. J. Smith, N. Cowern, B. Pawlak, F. Cristiano, R. Duffy, A. Claverie, C. Ortiz, P. Pichler, E. Lampin, and C. Zechner, Mater. Res. Soc. Symp. Proc. 810, C3.6 (2004).

${ }^{8}$ R. Kalyanaraman, V. Venezia, L. Pelaz, T. Haynes, H.-J. Gossmann, and C. Rafferty, Appl. Phys. Lett. 82, 2, 215 (2003).

${ }^{9}$ K. Winterbon, Radiat. Eff. 46, 181 (1980).

${ }^{10}$ V. Raineri, R. Schreutelkamp, F. Saris, K. Janssen, and R. Kaim, Appl. Phys. Lett. 58, 922 (1991).

${ }^{11}$ A. J. Smith, B. Colombeau, R. Gwilliam, E. Collart, N. Cowern, and B. Sealy, Mater. Res. Soc. Symp. Proc. 810, C3.8.1 (2004).

${ }^{12}$ A. J. Smith, B. Colombeau, N. Bennett, R. Gwilliam, N. Cowern, and B. Sealy, Mater. Res. Soc. Symp. Proc. 864, E7.1 (2005).

${ }^{13} \mathrm{~N}$. Bennett, A. Smith, B. Colombeau, R. Gwilliam, N. Cowern, and B. Sealy, Mater. Sci. Eng., B 124, 305 (2005).

${ }^{14}$ L. Shao, J. Zhang, J. Chen, D. Tang, P. Thomson, S. Patel, X. Wang, H. Chen, J. Liu, and W. Chu, Appl. Phys. Lett. 84, 3325 (2004). 